\title{
Journal of the Society for Gynecologic Investigation
}

\section{A Subnormal Plasma Volume in Formerly Preeclamptic Women is Associated with a Low Venous Capacitance}

Robert Aardenburg, Marc E. Spaanderman, Dorette A. Courtar, Hugo W. van Eijndhoven, Peter W. de Leeuw and Louis L. Peeters

Journal of the Society for Gynecologic Investigation 2005 12: 107

DOI: $10.1016 /$ j.jsgi.2004.09.002

The online version of this article can be found at:

http://rsx.sagepub.com/content/12/2/107

\author{
Published by: \\ (S)SAGE \\ http://www.sagepublications.com \\ On behalf of:

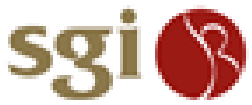 \\ Society for Gynecologic Investigation
}

Additional services and information for Journal of the Society for Gynecologic Investigation can be found at:

Email Alerts: http://rsx.sagepub.com/cgi/alerts

Subscriptions: http://rsx.sagepub.com/subscriptions

Reprints: http://www.sagepub.com/journalsReprints.nav

Permissions: http://www.sagepub.com/journalsPermissions.nav

Citations: http://rsx.sagepub.com/content/12/2/107.refs.html

>> Version of Record - Feb 1, 2005

What is This? 


\title{
A Subnormal Plasma Volume in Formerly Preeclamptic Women Is Associated With a Low Venous Capacitance
}

\author{
Robert Aardenburg, MD, Marc E. Spaanderman, MD, PhD, Dorette A. Courtar, MD, \\ Hugo W. van Eijndhoven, MD, Peter W. de Leeuw, MD, PhD, and \\ Louis L. Peeters, MD, PhD
}

\begin{abstract}
OBJECTIVE: Pregnancy induces a smaller rise in plasma volume in formerly preedamptic women with a pre-existent subnormal plasma volume than in their counterparts with a normal plasma volume. These women also have a three times higher recurrence rate of pregnancy-induced hypertensive disorders. In this study we tested the hypothesis that a subnormal plasma volume in these women is related to a lower capacitance of their venous compartment.

METHODS: In 31 nonpregnant formerly preedamptic women with a subnormal plasma volume and eight parous controls, we infused intravenously $500 \mathrm{~mL}$ of a modified gelatin solution over 30 minutes. Before and after infusion we measured the circulating levels of $\alpha$-atrial natriuretic peptide ( $\alpha$-ANP) and active plasma renin concentration (APRC). During volume loading, we recorded the change in heart rate, stroke volume, and cardiac output using pulse contour analysis. We measured the ratio of percent change in blood volume and percent change in cardiac output during volume loading as a marker for venous capacitance.

RESULTs: During volume loading, patients differed from controls by a larger rise in $\alpha-A N P$, pulse rate, and cardiac output, and by a lower estimated venous capacitance. The concomitant response of stroke volume and APRC did not differ appreciably between groups.

CONCLUSION: Formerly preedamptic women with a subnormal plasma volume differ from controls with a normal plasma volume by a reduced venous capacitance. These results support our hypothesis that, in these women, a subnormal plasma volume indicates the presence of a subnormal venous capacitance. (J Soc Gynecol Investig 2005;12:107-11) Copyright (C) 2005 by the Society for Gynecologic Investigation.
\end{abstract}

KEY WORDS: Preeclampsia, plasma volume, venous capacitance, pregnancy.

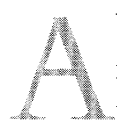

bout two thirds of nonpregnant normotensive formerly preeclamptic women have a subnormal plasma volume, ${ }^{1}$ which is accompanied by both a reduced venous compliance ${ }^{2}$ and a higher sympathetic activity in the autonomic control of the circulation. ${ }^{3,4}$ In their next pregnancy, these women differ from their counterparts with a normal plasma volume by a three times higher recurrence rate of hypertensive disorders, ${ }^{5}$ an observation indirectly supported by data from several other groups. ${ }^{6-9}$ Previously, we reported that in a next pregnancy, these women also differ from their counterparts with a normal plasma volume by a lack of plasma volume expansion and a rise instead of no change in $\alpha$-atrial natriuretic peptide ( $\alpha$-ANP) in the first 8 weeks. ${ }^{10}$

Under physiologic conditions, approximately $70 \%$ of the blood volume is located in the venous compartment, where it serves as a buffer to raise venous return in response to higher demands for systemic blood flow. ${ }^{11}$ The latter is mainly

From the Departments of Obstetrics and Gynecology, and Internal Medicine, University Hospital Maastricht, Maastricht, The Netherlands.

Address correspondence and reprint requests to: Robert Aardenburg, MD, Department of Obstetrics and Gynecology, University Hospital Maastricht, PO Box 5800, $6202 \mathrm{AZ}$ Maastricht, The Netherlands. E-mail: R.Aardenburg@og.unimaas.nl

Copyright (C) 2005 by the Society for Gynecologic Investigation.

Published by Elsevier Inc. achieved by venoconstriction, which raises cardiac preload by reducing venous capacitance. ${ }^{12}$ The latter is defined as the relationship between contained volume and distending pressure in the venous compartment ${ }^{13,14}$ in contrast to venous compliance, which is the ratio of a change in volume to the concomitant change in transmural distending pressure in the venous compartment. ${ }^{14}$ Compliance and capacitance are clearly interrelated, but capacitance describes the capacity to contain volume whereas compliance describes the elastic properties of the vascular wall. Although normotensive formerly preeclamptic women with a subnormal plasma volume have a reduced venous compliance, ${ }^{10}$ it is unclear whether the subnormal plasma volume is also accompanied by a lower venous capacitance.

The present study was designed to test the hypothesis that normotensive formerly preeclamptic women with a subnormal plasma volume have a lower venous capacitance than controls. To test this hypothesis we administered a volume load to a group of formerly preeclamptic women with a subnormal plasma volume and compared the responses to those obtained in a group of healthy parous controls with a normal plasma volume. 
Table 1. Demographic Variables

\begin{tabular}{lccc}
\hline & Low-PV & Controls & $P$ \\
\hline Age (y) & $31.1 \pm 0.7$ & $35.2 \pm 1.0$ & $<.05$ \\
Body mass index $\left(\mathrm{kg} \cdot \mathrm{m}^{-2}\right)$ & $25.5 \pm 0.7$ & $22.1 \pm 1.1$ & $<.05$ \\
Primiparity (\%) & $80.0 \%$ & $74.0 \%$ & $\mathrm{NS}$ \\
Smokers (\%) & $10.0 \%$ & 19.4 & $\mathrm{NS}$ \\
$\begin{array}{l}\text { Interval from pregnancy to } \\
\quad \text { study (y) }\end{array}$ & $1.6 \pm 0.2$ & $3.5 \pm 0.8$ & $<.05$ \\
$\begin{array}{l}\text { Plasma volume (mL/kg LBM) } \\
\text { Plasma volume }(\mathrm{mL})\end{array}$ & $44.2 \pm 1.6$ & $54.7 \pm 3.3$ & $<.05$ \\
$\begin{array}{l}\text { Forearm venous compliance } \\
\quad\left(\mathrm{mL} \cdot \mathrm{dL}^{-1} \cdot \mathrm{mmHg}^{-1}\right)\end{array}$ & $2576 \pm 67$ & $3015 \pm 176$ & $<.05$ \\
\hline
\end{tabular}

NS $=$ not significant; LBM $=$ lean body mass

\section{PATIENTS AND METHODS}

\section{Patients}

We performed this study in eight healthy parous controls and 31 nonpregnant normotensive women with both a recent history of early-onset ( $<34$ weeks) preeclampsia and/or HELLP (hemolysis, elevated liver enzymes, low platelets) syndrome, and a plasma volume of at least 2 SD below the mean of the control group determined at least 6 months postpartum ( $<48 \mathrm{~mL} / \mathrm{kg}$ lean body mass). Hypertension, preeclampsia, and HELLP syndrome were defined according to the criteria of the Report of the National High Blood Pressure Education Program Working Group on High Blood Pressure in Pregnancy. ${ }^{15}$ We recruited the controls by advertisement. We only enrolled women in the control group who were normotensive and had a history of uneventful pregnancy. Women in both groups had singleton pregnancies only. We started recruitment after approval of the study protocol by the university hospital's medical-ethical committee. After careful explanation of the protocol all participants gave written informed consent.

Table 2. Responses to Volume Loading

\begin{tabular}{|c|c|c|c|}
\hline & Low-PV & Controls & $\boldsymbol{P}$ \\
\hline$\alpha$-ANP (basal value, ng & & & \\
\hline $\left.\mathrm{L}^{-1}\right)$ & $66.6 \pm 3.6$ & $62.8 \pm 5.4$ & NS \\
\hline$\alpha$-ANP (postloading, ng & & & \\
\hline $\left.\mathrm{L}^{-1}\right)$ & $87.5 \pm 4.2$ & $61.1 \pm 6.0$ & $<.05$ \\
\hline APRC (basal value, $\mathrm{mU}$ & & & \\
\hline $\left.\mathrm{L}^{-1}\right)$ & $21.0 \pm 2.0$ & $19.4 \pm 6.3$ & NS \\
\hline APRC (postloading, $\mathrm{mU}$ & & & \\
\hline $\left.\mathrm{L}^{-1}\right)$ & $18.4 \pm 1.5$ & $16.8 \pm 4.8$ & NS \\
\hline $\begin{array}{l}\text { Heart rate (basal value, } \\
\text { beats } / \mathrm{min} \text { ) }\end{array}$ & $75 \pm 1$ & $76 \pm 3$ & NS \\
\hline $\begin{array}{l}\text { Heart rate (postloading, } \\
\text { beats } / \mathrm{min} \text { ) }\end{array}$ & $86 \pm 1$ & $79 \pm 4$ & NS \\
\hline $\begin{array}{l}\text { Stroke volume (basal value, } \\
\mathrm{mL} \text { ) }\end{array}$ & $89 \pm 3$ & $86 \pm 6$ & NS \\
\hline $\begin{array}{l}\text { Stroke volume } \\
\quad \text { (postloading, } \mathrm{mL} \text { ) }\end{array}$ & $97 \pm 3$ & $92 \pm 10$ & NS \\
\hline $\begin{array}{l}\text { Cardiac output (basal value, } \\
\mathrm{L} / \mathrm{min} \text { ) }\end{array}$ & $6.7 \pm 0.2$ & $6.6 \pm 0.5$ & NS \\
\hline $\begin{array}{l}\text { Cardiac output } \\
\text { (postloading, L/min) }\end{array}$ & $7.9 \pm 0.3$ & $7.0 \pm 0.5$ & $<.05$ \\
\hline
\end{tabular}

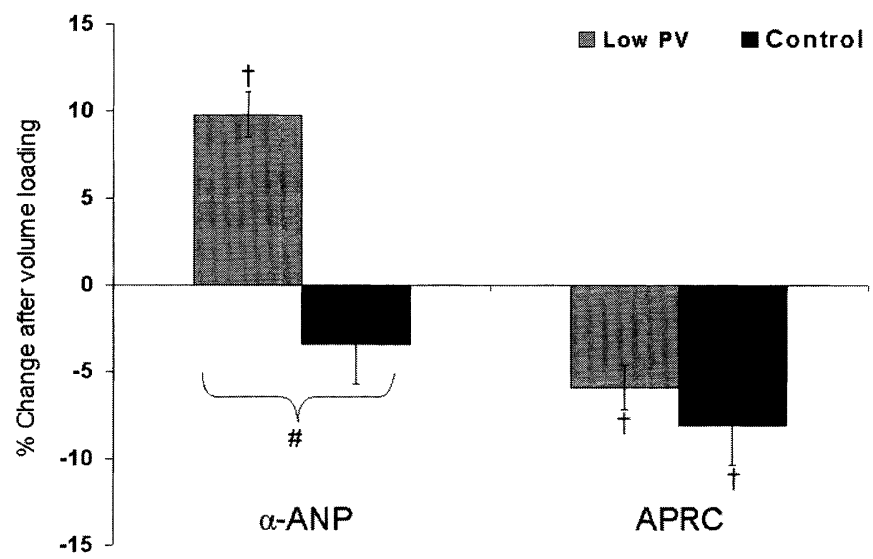

Figure 1. Percentage change $( \pm S E M)$ in $\alpha$-ANP and APRC in response to a volume load of $500 \mathrm{~mL}$. \#Significant intergroup difference $(P<.05)$. $\dagger$ Significant intragroup difference $(P<.05)$.

\section{Methods}

Measurements were performed in the follicular phase of the menstrual cycle (cycle day $5 \pm 3$ ). Participants refrained from smoking and consuming caffeine and/or alcohol-containing substances from the evening prior to study. During the measurements, the participants were comfortably laying in supine position under standardized conditions in a temperaturecontrolled room $(23 \pm 1 \mathrm{C})$.

Measurements were started after at least 30 minutes of acclimatization to the experimental conditions. Forearm venous compliance was measured by plethysmography as detailed elsewhere. ${ }^{2}$ Before and after infusion, we sampled blood for the measurement of the hematocrit and the circulating levels of $\alpha$-ANP $\left(\mathrm{ng} \cdot \mathrm{L}^{-1}\right.$ ) and of active plasma renin concentration (APRC, $\mathrm{mU} \cdot \mathrm{L}^{-1}$ ). Blood samples were collected in chilled tubes, put on ice during transport, and processed within minutes after collection to be stored at $-70 \mathrm{C}$ until analysis. $\alpha$-ANP and APRC were measured as detailed previously. ${ }^{10}$

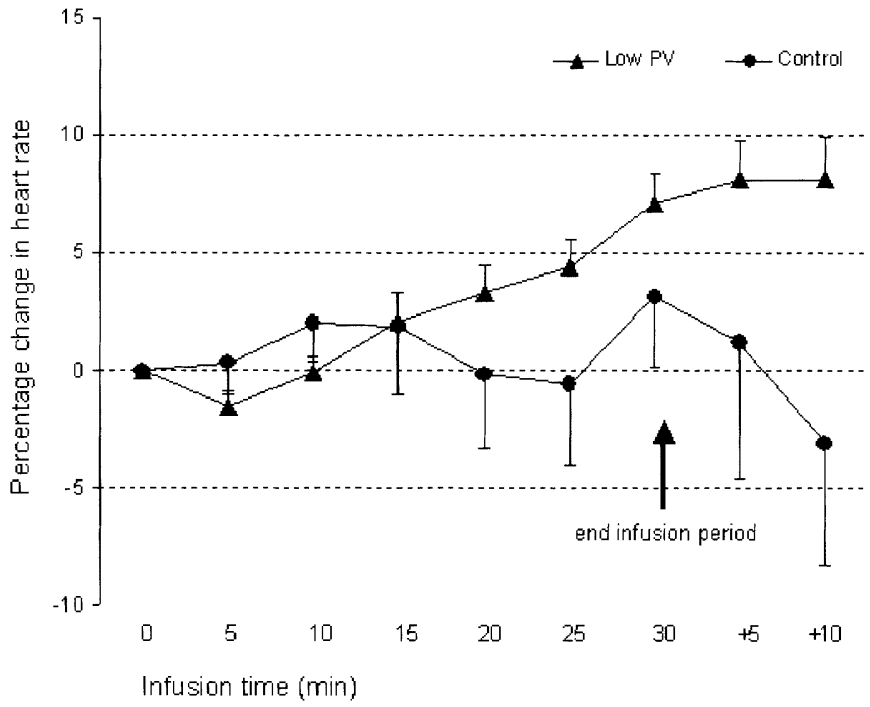

Figure 2. Percentage change $( \pm S E M)$ in heart rate in response to a volume load of $500 \mathrm{~mL}$ in 30 minutes and the 10 minutes following the infusion period. The area under the curve differed between the two groups (Mann-Whitney $U$ test, $P<.05$ ). 


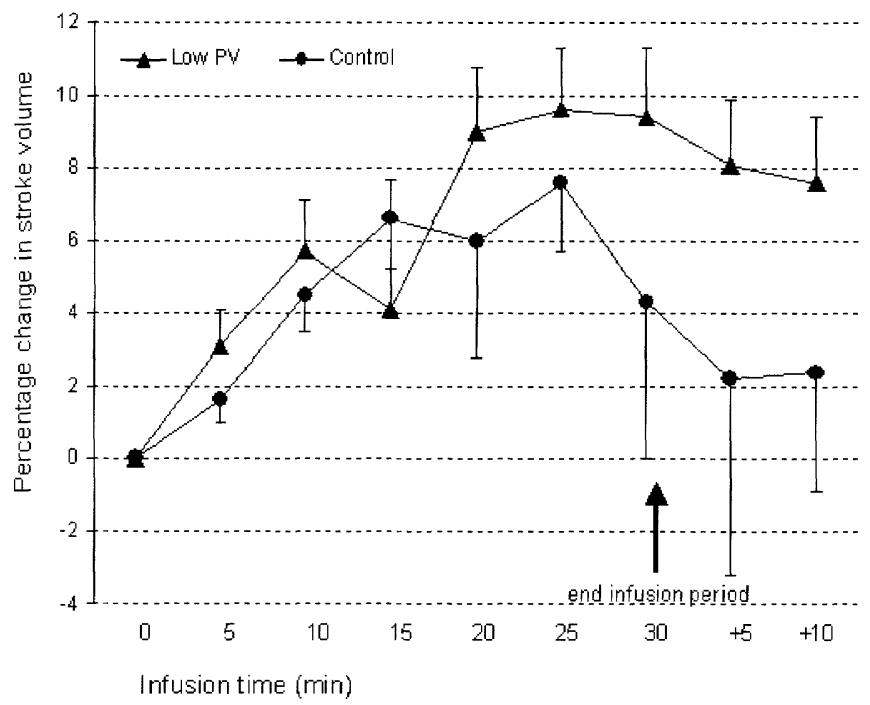

Figure 3. Percentage change $( \pm S E M)$ in stroke volume in response to a volume load of $500 \mathrm{~mL}$ during a 30 -minute period of infusion and the subsequent 10 minutes after discontinuation of the infusion. The area under the curve does not differ between groups.

We corrected the postinfusion levels of $\alpha$-ANP and APRC for dilution by multiplying the measured levels by the ratio of preand postinfusion hematocrit. Prior to volume loading, plasma volume was determined using dextran-70 indicator method as detailed previously. ${ }^{16}$ Plasma volume is expressed as milliliters per kilogram calculated lean body mass. ${ }^{1}$

After blood sampling, intravenous administration of a modified gelatin solution was started using an infusion pump at a constant rate of $16.7 \mathrm{~mL} \cdot \mathrm{min}^{-1}$. The infusion was discontinued after 30 minutes and thus after a total volume load of $500 \mathrm{~mL}$. We chose for a volume load of $500 \mathrm{~mL}$ to be infused in 30 minutes on the basis of a small pilot study aimed to assess optimal infusion rate and total volume load. We recorded (relative) changes in stroke

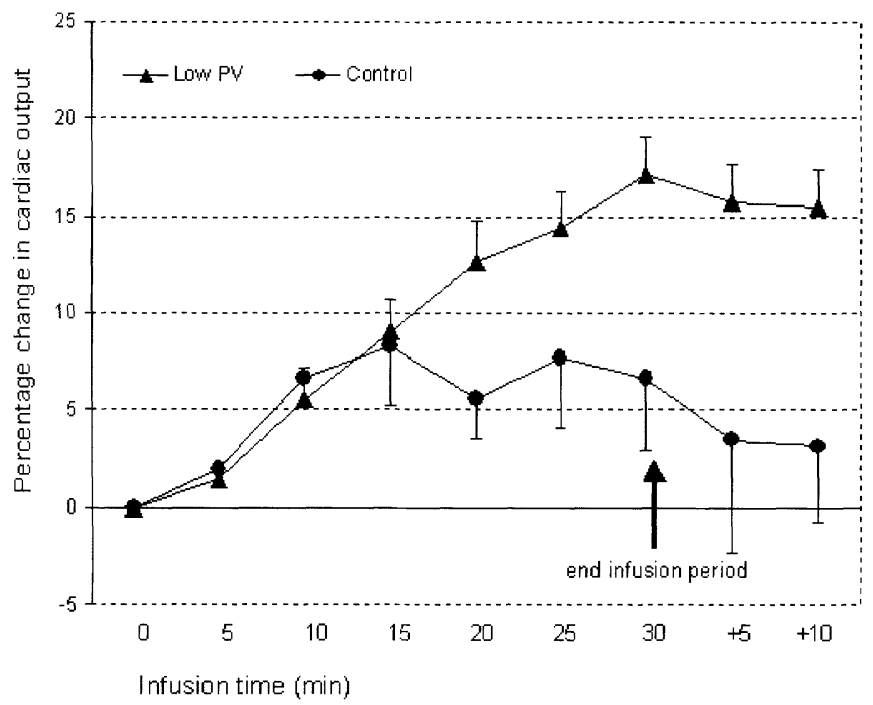

Figure 4. Percentage change $( \pm S E M)$ in cardiac output in response to a volume load of $500 \mathrm{~mL}$ in a 30 -minute infusion period and the 10 minutes after its discontinuation. The area under the curve differed between the two groups (Mann-Whitney $U$ test, $P<.01$ ).

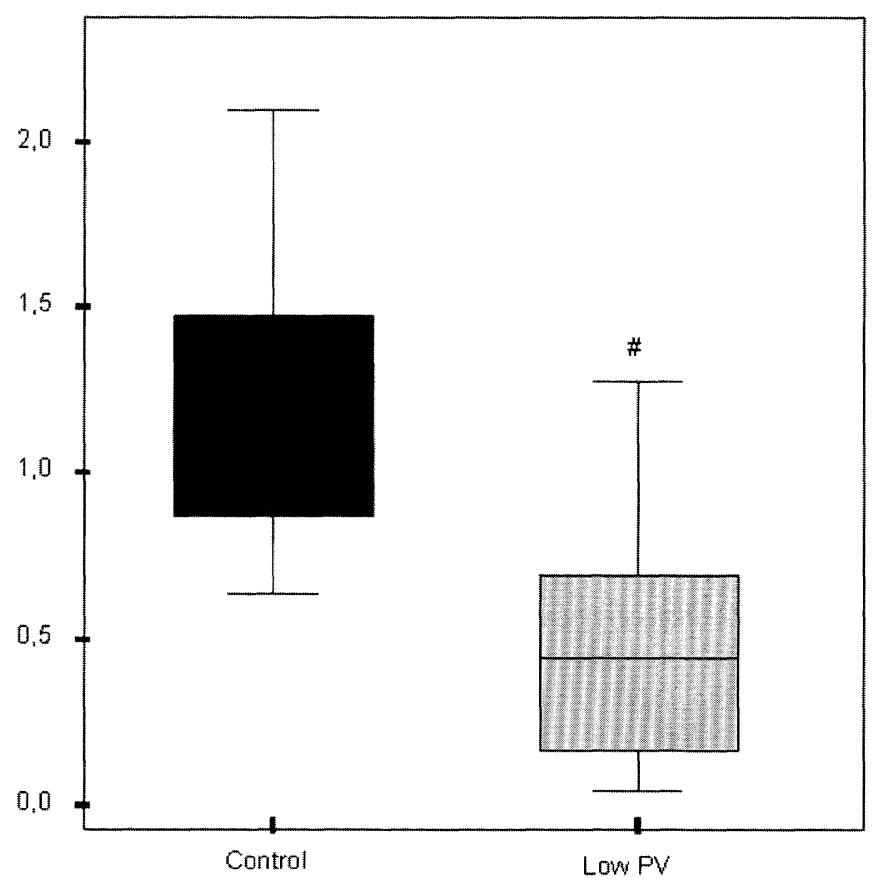

Figure 5. The slope of the linear regression line of the relative rise in cardiac output for a relative rise in plasma volume in the low-PV and control groups. Box plots show medians, interquartiles, and ranges. \#Significant difference between the two groups $(P<.05)$.

volume $(\mathrm{mL})$, heart rate (beats $\left.\cdot \min ^{-1}\right)$, and cardiac output $(\mathrm{L}$. $\min ^{-1}$ ) in response to volume loading, using continuous beat-tobeat pulse contour analysis with the Portapress device (TNOBiomedical Instrumentation, Amsterdam, The Netherlands). ${ }^{17}$ This technique has been validated for estimating intra-individual changes in stroke volume over time. ${ }^{18-20} \mathrm{We}$ assessed the hemodynamic responses to volume loading on the basis of Portapress recordings at 5-minute intervals throughout the infusion period and the subsequent 10 minutes afterwards.

Venous capacitance is an estimate of venous filling in steady state. ${ }^{14}$ Depending on size and compliance of the venous bed, volume loading will raise unstressed volume until cardiac preload, and with it cardiac output, begins to increase. The maximum volume load, accommodated without a rise in preload, can be expected to vary as a function of venous capacitance. It follows that an estimate of venous capacitance can be obtained by subjecting the vascular bed to a standardized procedure of volume loading. We adopted a method to reflect venous capacitance by calculating the slope of the linear regression line of the relative rise in cardiac output for a relative rise in plasma volume. The relative change in plasma volume was obtained by taking the ratio of pre- and postinfusion hematocrit.

\section{Statistical Methods}

The intergroup differences and those observed in the response to volume loading in $\alpha$-ANP and APRC and venous capacitance were tested by Mann-Whitney $U$ test. For the intergroup difference in changes in pulse rate, stroke volume, and cardiac output in response to volume loading, the area under 
the curve was calculated and differences were tested by MannWhitney $U$ test. Intragroup changes in $\alpha$-ANP and APRC as a result of volume loading were tested using with the Wilcoxon signed-rank test. A $P$ value less than .05 was considered statistically significant.

\section{RESULTS}

Table 1 lists the demographic characteristics of both study groups. The patient group (low-PV) had a higher body mass index, lower age, and, obviously, a lower plasma volume, but comparable parity and a shorter interval between pregnancy and the time of study relative to the control group. Among the multiparous women, $50 \%$ had two pregnancies and $50 \%$ had three pregnancies in both patients and the control group.

Table 2 lists the absolute values of responses to volume loading. Women in the low-PV group have a significant increase in $\alpha$-ANP and cardiac output in response to volume loading.

The relative changes in response to volume loading in $\alpha$-ANP and APRC are displayed in Figure 1. Women in the low-PV group differed from controls by an increase in $\alpha$-ANP. Responses of APRC to volume loading were similar in both groups.

Relative hemodynamic changes in response to volume loading are depicted in Figures 2, 3, and 4. While the response in heart rate (Figure 2) was higher in the low-PV group, the response in stroke volume did not differ between the two groups (Figure 3). The latter lack of difference might be power-related. Figure 4 illustrates the response in cardiac output to volume loading. Volume loading induced an initial rise in both groups; however, only in the low-PV group, cardiac output continued to increase after the first 15 minutes of volume loading, an effect that persisted after discontinuation of volume loading.

The slope of the linear regression line of the relative rise in cardiac output for a relative rise in plasma volume is shown in Figure 5. Relative to controls, this slope was $70 \%$ lower in the low-PV group.

\section{DISCUSSION}

The response to acute volume loading in formerly preeclamptic women with a subnormal plasma volume differs from that in parous controls by both a larger rise in cardiac output and a rise instead of no change in $\alpha$-ANP. Both effects are consistent with a reduced capacity to accommodate a relatively modest volume load in the vascular bed. The observed rise in cardiac output probably indicates a volume shift from the venous to the arterial bed, whereas the observed higher circulating levels of $\alpha$-ANP will cause fluid loss from the vascular bed by accelerated natriuresis and leakage of fluid to the interstitium in conjunction with a increased capillary permeability. ${ }^{21,22} \mathrm{Ve}-$ nous capacitance can be expected to vary with the amount of extra blood that the venous bed is able to accommodate. The higher slope of the linear regression line of the relative rise in cardiac output for a relative rise in plasma volume in the low-PV group suggests that a subnormal plasma volume in formerly preeclamptic women indicates a reduced venous capacitance.

The venous capacitance consists of a static (size of the venous compartment) and a dynamic component (total venous compliance). Because cardiac output and venous return are closely correlated, we used changes in cardiac output as an estimate for the concomitant changes in venous return. As our estimate for venous capacitance varied independently from that in the concomitantly measured forearm venous compliance, the latter did not seem to be a confounder of venous capacitance.

In a previous study we reported that formerly preeclamptic women with a subnormal plasma volume respond to a new pregnancy with absent or less plasma volume expansion than parous controls with a normal plasma volume. ${ }^{2}$ The concomitant rise in $\alpha$-ANP as opposed to no change in uneventful pregnancy $^{10}$ supports the concept that also during pregnancy, subnormal plasma volume expansion results from a limited capacity to expand the unstressed volume in the venous bed, and thus venous capacitance. From these inferences we conclude that these women have a subnormal venous capacitance, which limits their ability to expand plasma volume in pregnancy.

Capacitance is an important characteristic of the venous bed as it represents a buffer, which can be mobilized in response to a higher demand for venous return. ${ }^{13}$ Particularly in conditions of prolonged increases in cardiac output as seen in pregnancy, this buffer is important, because the alternative option to raise cardiac output would be by increasing the sympathetic drive in the autonomic control of the cardiovascular system. The latter is not only less efficient and associated with extra strain exerted on heart and arteries due to increased shear stress, it also induces a redistribution of systemic blood flow at the expense of nonvital tissues, including the uterus.

The latter may cause the development of a hyperdynamic circulation. Although there is limited consensus about the hemodynamics of preeclampsia, several studies seem to confirm that the early stage of preeclampsia is characterized by a hyperdynamic circulation. ${ }^{23-26}$ Furthermore, a hyperdynamic circulation interferes with the circulatory adaptation to pregnancy and the growth of the uteroplacental perfusion and, thus, is associated with a greater risk to develop pregnancyinduced hypertensive disorders.

Because we did not collect data about natriuresis during volume loading, we can only draw limited conclusions about volume-regulatory function in these women. It remains unclear why in some individuals plasma volume may be reduced.

In this study, we did not find any differences in basal heart rate. However, hyperactivity of the sympathetic nervous system $^{3,4}$ may be associated with an increase in venous tone and consequently a subnormal venous capacitance. Angiotensinogen polymorphisms ${ }^{27}$ may also have an influence on venous capacitance. On the other hand, in line with the Barker hypothesis, it is also possible that some of these women have an environmentally induced inborn reduction of venous capacitance. $^{28}$ 


\section{CONCLUSION}

The capacitance of the venous compartment in normotensive formerly preeclamptic women with a subnormal plasma volume is substantially lower than that in healthy parous controls. The latter may predispose for circulatory maladaptation to pregnancy, and with it for pregnancy-induced hypertensive disorders.

\section{REFERENCES}

1. Spaanderman ME, Ekhart TH, van Eyck J, Cheriex EC, de Leeuw PW, Peeters LL. Latent hemodynamic abnormalities in symptom-free women with a history of preeclampsia. Am J Obstet Gynecol 2000;182:101-7.

2. Spaanderman ME, Willekes C, Hoeks AP, Ekhart TH, Peeters LL. The effect of pregnancy on the compliance of large arteries and veins in healthy parous control subjects and women with a history of preeclampsia. Am J Obstet Gynecol 2000;183: 1278-86.

3. Bernstein IM, Ziegler WF, Leavitt T, Badger GJ. Uterine artery hemodynamic adaptations through the menstrual cycle into early pregnancy. Obstet Gynecol 2002;99:620-4.

4. Bernstein IM, Shapiro RE, Whitsel A, Schonberg AL. Relationship of plasma volume to sympathetic tone in nulliparous women. Am J Obstet Gynecol 2003;188:938-42.

5. Aardenburg R, Spaanderman ME, Ekhart TH, van Eijndhoven HW, van der Heijden OW, Peeters LL. Low plasma volume following pregnancy complicated by pre-eclampsia predisposes for hypertensive disease in a next pregnancy. Br J Obstet Gynecol 2003;110:1001-6.

6. Goodlin RC. Maternal plasma volume and disorders of pregnancy. Br Med J (Clin Res Ed) 1984;288:1454-5.

7. Silver HM, Seebeck M, Carlson R. Comparison of total blood volume in normal, preeclamptic, and nonproteinuric gestational hypertensive pregnancy by simultaneous measurement of red blood cell and plasma volumes. Am J Obstet Gynecol 1998; 179:87-93.

8. Bernstein IM, Meyer MC, Osol G, Ward K. Intolerance to volume expansion: A theorized mechanism for the development of preeclampsia. Obstet Gynecol 1998;92:306-8.

9. Hunyor SN. Vascular, volume, and cardiac response to normal and hypertensive pregnancy. Hypertension 1984;6:III129-32.

10. Spaanderman M, Ekhart T, van Eyck J, de Leeuw P, Peeters L. Preeclampsia and maladaptation to pregnancy: A role for atrial natriuretic peptide? Kidney Int 2001;60:1397-406.

11. Hays PM, Cruikshank DP, Dunn LJ. Plasma volume determination in normal and preeclamptic pregnancies. Am J Obstet Gynecol 1985;151:958-66.
12. Tyberg JV. How changes in venous capacitance modulate cardiac output. Pflugers Arch 2002;445:10-7.

13. Rothe CF. Reflex control of veins and vascular capacitance. Physiol Rev 1983;63:1281-342.

14. Pang CC. Autonomic control of the venous system in health and disease: Effects of drugs. Pharmacol Ther 2001;90:179-230.

15. Report of the National High Blood Pressure Education Program Working Group on High Blood Pressure in Pregnancy. Am J Obstet Gynecol 2000;183:S1-22.

16. van Kreel BK, van Beek E, Spaanderman ME, Peeters LL. A new method for plasma volume measurements with unlabeled dextran-70 instead of ${ }^{125}$ I-labeled albumin as an indicator. Clin Chim Acta 1998;275:71-80.

17. Wesseling KH, de Wit B, Weber JAP, Smith NT. A simple device for the continuous measurement of cardiac output. Its model basis and experimental verification. Adv. Cardiovasc Phys 1983;5(Suppl II):16-52.

18. Jansen JR, Wesseling KH, Settels JJ, Schreuder JJ. Continuous cardiac output monitoring by pulse contour during cardiac surgery. Eur Heart J 1990;11(Suppl I):26-32.

19. Stok WJ, Baisch F, Hillebrecht A, Schulz H, Meyer M, Karemaker JM. Noninvasive cardiac output measurement by arterial pulse analysis compared with inert gas rebreathing. J Appl Physiol 1993;74:2687-93.

20. Gratz I, Kraidin J, Jacobi AG, deCastro NG, Spagna P, Larijani GE. Continuous noninvasive cardiac output as estimated from the pulse contour curve. J Clin Monit 1992;8:20-7.

21. Wijeyaratne CN, Moult PJ. The effect of alpha human atrial natriuretic peptide on plasma volume and vascular permeability in normotensive subjects. J Clin Endocrinol Metab 1993; 76:343-6.

22. Lowe SA, Zammit VC, Mitar D, Macdonald GJ, Brown MA. Atrial natriuretic peptide and plasma volume in pregnancyinduced hypertension. Am J Hypertens 1991;4:897-903.

23. Mabie WC, Ratts TE, Sibai BM. The central hemodynamics of severe preeclampsia. Am J Obstet Gynecol 1989;161:1443-8.

24. Easterling TR, Benedetti TJ, Schmucker BC, Millard SP. Maternal hemodynamics in normal and preeclamptic pregnancies: A longitudinal study. Obstet Gynecol 1990;76:1061-9.

25. Bosio PM, McKenna PJ, Conroy R, O'Herlihy C. Maternal central hemodynamics in hypertensive disorders of pregnancy. Obstet Gynecol 1999;94:978-84.

26. Visser W, Wallenburg HC. Central hemodynamic observations in untreated preeclamptic patients. Hypertension 1991;17: 1072-7.

27. Bernstein IM, Ziegler W, Stirewalt WS, Brumsted J, Ward K. Angiotensinogen genotype and plasma volume in nulligravid women. Obstet Gynecol 1998;92:171-3.

28. Poston L. Intrauterine vascular development: programming effects of nutrition on vascular function in the new born and adult. Nutr Health 2001;15:207-12. 